\title{
Effect of Therapeutic Exercises and ADL Instructions in Low Back Pain During Pregnancy
}

\author{
Subhan $\mathrm{F}^{1}$, Uddin $\mathrm{MT}^{2}$, Hassan $\mathrm{MK}^{3}$, Walid $\mathrm{CM}^{4}$, Sadeque $\mathrm{ABM}^{5}$
}

\begin{abstract}
Aim of this study is to educate pregnant women about posture and application of biomechanical principles in functional and work related activities and to prevent low back pain with help of Exercise Program and Education.

Patients were randomly allocated in two groups. Group A included 30 patients and they received traditional antenatal care. Group $B$ included more 30 patients and received therapeutic exercise and ADL instructions. They had one visit every two week for six weeks. In each visit both groups were evaluated for variables including pain, tenderness, mobility index and sleep. Pain was assessed by subjective intensity and $V A S$; tenderness was evaluated by tenderness index, mobility index by scoter test and SLR (straight leg rising).

All the relevant collected data were recorded in prescribed data sheet and analyzed by using computer based statistical packages for social science (SPSS). A ' $p$ ' value $<0.05$ was considered as significant. Student's't' test and Chi-square test was done to see the level of significance as required.

The Study concluded that the back care in the form of Exercise Program and Postural Education given to women as early in their pregnancy as possible may prevent back pain or decrease the severity of back pain if it occurs.
\end{abstract}

Keywords: Gravida, Biomechanical principles, Posture, Centre of gravity.

1. Corresponding Author:

Dr. Fauzia Sobhan MBBS, FCPS

Medical Officer

Physical Medicine and Rehabilitation Department

BIRDEM General Hospital, Shahbag, Dhaka.

2. Prof Dr. Md. Taslim Uddin MBBS, FCPS

Professor, Department of Physical Medicine and Rehabilitation

Bangabandhu Sheik Mujib Medical University, Dhaka.

3. Dr. Muhammad Kamrul Hassan MBBS, FCPS

Assistant Professor

Physical Medicine and Rehabilitation Department

Shahabuddin Medical College Hospital, Dhaka.

4. Dr. Chowdhury Mohammad Walid

Assistant Professor

Physical Medicine and Rehabilitation Department

Sylhet Womens Medical College, Sylhet.

5. Dr. A.B.M. Zafar Sadeque

Assistant Registrar, Department of Physical Medicine

Rajshahi Medical College Hospital, Rajshahi.

\section{Introduction}

Pregnancy is a time of tremendous musculoskeletal, physical and emotional change and yet is a condition of wellness. Back pain is one of the most common complaints during gestation. $50 \%-90 \%$ of pregnant women, low back pain develop at some point during pregnancy ${ }^{1}$. Systematic review of 28 studies done by $\mathrm{Wu}$ WH, Mijer OG, Uegaki K, Mens JM, Van Dieen JH, Wuisman PL, that used the two terms "pregnancy related pelvic girdle pain" and "pregnancy related low back pain" found that prevalence ranged from $3.9 \%-89.9 \%$ (mean $45.3 \%)^{2}$. Fast A .et al made a cross-sectional study among 200 women in $24-36$ hours after birth and he showed that $56 \%$ of the patients suffer from low back pain during pregnancy ${ }^{3}$. As the fetus grows, a woman's abdominal wall stretches to accommodate the expanding womb. During pregnancy the hormone Relaxin is present in ten times its normal concentration in the female body. It relaxes joints in the pelvis. It also causes abnormal motion in many joints of the body causing inflammation and pain during the increased lordosis of pregnancy combined with the effects of Relaxin on the joints of the pelvis and the weight of the gravid uterus with result anterior shift in the centre of gravity all contribute to complaints of low back pain.

Prevention and treatment of back pain related to pregnancy would thus have considerable implications for the women themselves \& for society in terms of quality of life, public health costs and productivity. Low back Pain affects the physical, physiological, emotional, financial and social aspects of personal life.

The desire and determination for a healthy back during pregnancy is placed largely on each individual woman who will need education and support to adhere to a needed exercise program. Effective pain relief can often best be achieved by bed rest and participation in exercise programs $\mathrm{s}^{4}$. The goal of therapeutic exercise during pregnancy is to improve or maintain muscle tone and not to control weight gain or to correct posture ${ }^{5}$.

The Physiatrist, however, may possess the best functional understanding of all specialists in applying Physical Medicine and Rehabilitation principles to the treatment and management of low back pain.

In our country, pregnant women are not aware about their posture, activities of daily living during pregnancy. Education is the first step in effective treatment of backache during pregnancy. Mothers should be informed about back care and attention to posture, backache should resolve and also prevent back pain after pregnancy. So, this study is undertaken to see the effect of therapeutic 
exercise and ADL instructions in back pain during pregnancy.

\section{Materials and Methods}

Study design: Prospective, randomized, observational study.

Place of the study:

Department of Physical Medicine and Rehabilitation, BSMMU, Shahbag, Dhaka.

Department of Obstetric and Gynecology, BSMMU, Shahbag, Dhaka.

Time and duration of the study:

For a period of one year from March 2008 to February 2009.

Sample size:

A total 60 patient was seen during this period. Proper clinical assessment was done following standard protocol for diagnosis, assessment and to find out any high risk factors.

Selection of patient

Inclusion criteria:

1. Pregnant women in the 2 nd and 3 rd trimester in the age group 20yrs - 35yrs.

2. Patients without risk factors of pregnancy

3. Patients with residence of Dhaka city who were able to attend follow up

Exclusion criteria:

1. Patient age group before $20 \mathrm{yrs}$ and after $35 \mathrm{yrs}$.

2. Patient with any risk factors of pregnancy - cardiac disease or constrictive lung disease. second- or third-trimester bleeding, pregnancy-induced hypertension, preterm labor with present or previous pregnancies, intrauterine growth retardation, incompetent cervix, placenta previa, and premature rupture of membrane, diabetes mellitus, multiple pregnancy etc.

3. Patients from outside Dhaka city were excluded from the study.

This prospective, observational study was carried out in the department of Physical Medicine and Rehabilitation, BSMMU during March 08-February 09.This group of patients were mostly attended antenatal clinic of BSMMU. In the first contact with patients a brief discussion were made about study and then they were referred to Rehabilitation department. A verbal consent was taken from all participants after discussion of the nature of the study. After proper history taking, initial evaluations, clinical diagnosis of low back pain in pregnant women were surveyed by structured questionnaires. Patients were recruited for the study according to inclusion and exclusion criteria. Patients were randomly allocated in two groups. Group A included 30 patients and they received traditional antenatal care. Group B included more 30 patients and received therapeutic exercise and ADL instructions. They had one visit every two week for six weeks. In each visit both groups were evaluated for variables including pain, tenderness, mobility index and sleep. Pain was assessed by subjective intensity and VAS; tenderness was evaluated by tenderness index, mobility index by schober test and SLR (straight leg rising).

Statistical analysis: All the relevant collected data were recorded in prescribed data sheet and analyzed by using computer based statistical packages for social science (SPSS). A 'p' value $<0.05$ was considered as significant. Student's't' test and Chi-square test was done to see the level of significance as required.

Ethical consideration:

In this study, after recruitment of the subjects, the nature of study was described thoroughly to the patients and the verbal consent of the patients were taken properly. Every patient was given due respect- they had the opportunity to withdraw themselves from the study at any time but treatment facilities were same for them. All the data were kept under lock and key and confidentiality was maintained strictly.

\section{Result}

Table I Age distribution of the study subjects

\begin{tabular}{llcl}
\hline Age (years) & $\begin{array}{c}\text { Group A } \\
(\mathrm{n}=28)\end{array}$ & $\begin{array}{c}\text { Group B } \\
(\mathrm{n}=30)\end{array}$ & P value \\
& No. $(\%)$ & No. $(\%)$ & \\
\hline $20-23$ & $12(42.9)$ & $14(46.7)$ & \\
$24-29$ & $13(46.4)$ & $13(43.3)$ & $0.958 \mathrm{~ns}$ \\
$30-35$ & $3(10.7)$ & $3(10.0)$ & \\
\hline
\end{tabular}

Table-I show age distribution of the study subjects. In group A and group B, respectively, 12 (42.9\%) and 14 (46.7\%) patients belonged to age group 2023 years, 113 (46.4\%) and 13 (43.3\%) belonged to age group 2429 years, and $3(10.7 \%)$ each belonged to age group 3035 years. Statistically age did not show any significant variation between groups.

Table-II Distribution of occupation of the study subjects

\begin{tabular}{llll}
\hline Occupation & $\begin{array}{c}\text { Group A } \\
(\mathrm{n}=28)\end{array}$ & $\begin{array}{c}\text { Group B } \\
(\mathrm{n}=30)\end{array}$ & P value \\
& No. $(\%)$ & No. $(\%)$ & \\
\hline House wife & $23(82.1)$ & $26(86.7)$ & \\
& & & $0.634 \mathrm{~ns}$ \\
Service holder & $5(17.9)$ & $4(13.3)$ & \\
\hline
\end{tabular}


Table II show occupation of the study subjects. In group A and group B, respectively, $23(82.1 \%)$ and $26(86.7 \%)$ subjects were housewives, and $5(17.9 \%)$ and $4(13.3 \%)$ were service holder. Statistically occupation did not show any significant variation between groups.

Table-III Parity distribution of the study subjects

\begin{tabular}{lcll}
\hline Parity & $\begin{array}{c}\text { Group A } \\
(\mathrm{n}=28)\end{array}$ & $\begin{array}{l}\text { Group B } \\
(\mathrm{n}=30)\end{array}$ & P value \\
& No.(\%) & No.(\%) & \\
\hline Primi & $19(67.9)$ & $17(56.7)$ & \\
& & & $0.380 \mathrm{~ns}$ \\
Multi & $9(32.1)$ & $13(43.3)$ & \\
\hline
\end{tabular}

Table III show parity of the study subjects. In group A and group B, respectively, 19 (67.9\%) and 17 (56.7\%) subjects were primiparous, and $9(32.1 \%)$ and $13(43.3 \%)$ were multiparous. Statistically parity did not show any significant variation between groups.

Table-IV. Assessment of pain score (VAS)

\begin{tabular}{lccl}
\hline VAS score & $\begin{array}{c}\text { Group A } \\
(\mathrm{n}=28)\end{array}$ & $\begin{array}{c}\text { Group B } \\
(\mathrm{n}=30)\end{array}$ & P value \\
& $\begin{array}{c}\text { Mean } \pm \mathrm{SD}) \\
(\mathrm{Mean} \pm \mathrm{SD})\end{array}$ & \\
\hline Week 0 & $7.54 \pm 0.51$ & $8.03 \pm 0.41$ & $0.0001^{* * *}$ \\
Week 2 & $7.39 \pm 0.50$ & $7.30 \pm 0.54$ & $0.497 \mathrm{~ns}$ \\
Week 4 & $7.18 \pm 0.55$ & $6.57 \pm 0.82$ & $0.002^{* *}$ \\
Week 6 & $6.86 \pm 0.65$ & $5.70 \pm 1.02$ & $0.0001^{* * *}$
\end{tabular}

Assessment of pain scores (VAS) have been shown in Table IV. Percent reduction in pain score at week 2, 4 and 6 was higher in group B $(9.07 \%, 18.31 \%$ and $29.13 \%$, respectively) compared to group A $(1.47 \%, 4.34 \%$ and $8.48 \%$, respectively.

Table V. Assessment of tenderness

\begin{tabular}{lccc}
\hline Tenderness & $\begin{array}{c}\text { Group A } \\
(\mathrm{n}=28)\end{array}$ & $\begin{array}{c}\text { Group B } \\
(\mathrm{n}=30)\end{array}$ & P value \\
& No. $(\%)$ & No. $(\%)$ & \\
\hline Week 0 & & & $0.0001^{* * *}$ \\
Grade 2 & $14(50.0)$ & $2(6.7)$ & \\
Grade 3 & $14(50.0)$ & $28(93.3)$ & \\
Week 2 & & & $0.189 \mathrm{~ns}$ \\
Grade 2 & $17(60.7)$ & $23(76.7)$ & \\
Grade 3 & $11(39.3)$ & $7(23.3)$ & \\
Week 4 & & & $0.0001^{* * *}$ \\
Grade 1 & $1(3.6)$ & $19(63.3)$ &
\end{tabular}

\begin{tabular}{lcll} 
Grade 2 & $21(75.0)$ & $7(23.3)$ & \\
Grade 3 & $6(21.4)$ & $4(13.3)$ & \\
Week 6 & & & $0.0001^{* * *}$ \\
Grade 1 & $8(28.6)$ & $25(83.3)$ & \\
Grade 2 & $13(46.4)$ & $4(13.3)$ & \\
Grade 3 & $7(25.0)$ & $1(3.3)$ & \\
\hline
\end{tabular}

Table VI. Assessment of sleep

\begin{tabular}{lccc}
\hline Sleep & $\begin{array}{c}\text { Group A } \\
(\mathrm{n}=28)\end{array}$ & $\begin{array}{c}\text { Group B } \\
(\mathrm{n}=30)\end{array}$ & P value \\
& No.(\%) & No.(\%) & \\
Week 0 & & & \\
Grade 2 & $13(46.4)$ & $3(10.0)$ & \\
Grade 3 & $15(53.6)$ & $27(90.0)$ & \\
Week 2 & & & $0.197 \mathrm{~ns}$ \\
Grade 1 & 0 & $2(6.7)$ & \\
Grade 2 & $17(60.7)$ & $21(70.0)$ & \\
Grade 3 & $11(39.3)$ & $7(23.3)$ & \\
Week 4 & & & $0.0001^{* * *}$ \\
Grade 1 & $1(3.6)$ & $19(63.3)$ & \\
Grade 2 & $22(78.6)$ & $5(16.7)$ & \\
Grade 3 & $5(17.9)$ & $6(20.0)$ & \\
Week 6 & & & $0.0001^{* * *}$ \\
Grade 1 & $8(28.6)$ & $24(80.0)$ & \\
Grade 2 & $16(57.1)$ & $5(16.7)$ & \\
Grade 3 & $4(14.3)$ & $1(3.3)$ & \\
\hline
\end{tabular}

Table VII Assessment of mobility index by SLR test

$\begin{array}{lccl}\text { Mobility } & \begin{array}{c}\text { Group A } \\ (\mathrm{n}=28)\end{array} & \begin{array}{c}\text { Group B } \\ (\mathrm{n}=30)\end{array} & \text { P value } \\ & (\text { Mean } \pm \text { SD }) & (\text { Mean } \pm \text { SD }) & \\ \text { Week 0 } & 62.32 \pm 2.54 & 59.33 \pm 3.41 & 0.0001^{\star * *} \\ \text { Week 2 } & 63.04 \pm 2.49 & 63.33 \pm 3.30 & 0.701 \mathrm{~ns} \\ \text { Week 4 } & 64.11 \pm 3.61 & 67.17 \pm 4.09 & 0.004^{* *} \\ \text { Week 6 } & 65.89 \pm 3.35 & 75.00 \pm 7.66 & 0.0001^{* * *}\end{array}$

Table VII show mobility index of group A and group B patients. Mean $( \pm \mathrm{SD})$ mobility index (SLR) was significantly high $(\mathrm{P}<0.001)$ in group A $(62.32 \pm 2.54 \mathrm{o})$ in comparison to group B $(59.33 \pm 3.410)$. 
Table VIII. Assessment of mobility index by Schober test

\begin{tabular}{|c|c|c|c|}
\hline $\begin{array}{l}\text { Mobility } \\
(\mathrm{cm})\end{array}$ & $\begin{array}{c}\text { Group A } \\
(\mathrm{n}=28) \\
(\text { Mean } \pm S D)\end{array}$ & $\begin{array}{c}\text { Group B } \\
(n=30) \\
(\text { Mean } \pm \text { SD })\end{array}$ & $\mathrm{P}$ value \\
\hline Week 0 & $3.23 \pm 0.25$ & $2.98 \pm 0.21$ & $0.0001^{* * *}$ \\
\hline Week 2 & $3.30 \pm 0.25$ & $3.35 \pm 0.27$ & $0.497 \mathrm{~ns}$ \\
\hline Week 4 & $3.41 \pm 0.27$ & $3.72 \pm 0.41$ & $0.002^{* *}$ \\
\hline Week 6 & $3.57 \pm 0.33$ & $3.87 \pm 0.32$ & $0.001^{* *}$ \\
\hline
\end{tabular}

\section{Discussion}

The back pain of pregnancy is not trivial for some women, it may be the beginning of lifelong chronic back pain, for others it may cause considerable disability and distress during and for a variable period after pregnancy. Spinal and pelvic insufficiency is common during pregnancy. There is also association between type of work and the development of low back pain.

There are four main mechanisms which are proposed as contributory to the pathogenesis of LBP during pregnancy.

1. Direct pressure of the fetus and gravid uterus on lumbocral nerve roots.

2. Strained spinal antigravity muscles due to inefficient function of the anterior abdominal wall muscles.

3. Increased lumber lordosis due to increasing size of the uterus and its contents in a relatively short time during pregnancy, and

\section{Laxity of ligaments.}

Pregnant women deserve to have their complaints taken seriously and their back pain assessed and treated. Although it may not be possible to eliminate back pain in susceptible women, the literature suggests that it is possible to reduce it and ameliorate its effects. Research needs to address the issue of prevention as well as treatment, and clients must be followed for longer periods of time to gain better understanding of the natural history of pregnancy related back pain.

Although more studies are needed to elucidate the pathogenesis and risk factors of LBP during pregnancy, we suggest that back care in the form of education in $\mathrm{m}$ offered as a group of pregnant women prove to develop LBP during pregnancy, as early in their pregnancy's possible, may prevent LBP or result is less troublesome and severe LBP during pregnancy. Results from the statistical analysis show that there were highly significant results in the areas of Intensity, Sitting, Sleeping, Personal Care, Walking, Standing, Social Life and Traveling $(\mathrm{p}<$.005) The VAS $(\mathrm{P}<$.OO5) (Table and graph 4) was highly significant which is supported by Mantle et al,
$1977^{6}$. In their studies they stated that pain may diminish through exercises and education.

In keeping with the aims of the study it was seen that exercises and postural education in pregnant women is necessary both in prevention of low back pain as well as management of pain due to postural imbalance during pregnancy. The goal that the mother would be healthy throughout the pregnancy and hence would have direct effect on child's health is met. Many of the women had not only a physical sense of well being but also a psychological well being. The number of the patients was small and there were some limitations of this trial.

Therefore, no firm conclusion could be drawn. The information collected need verification by larger long-term follow up studies. Considering the information gathered from this study, it can be concluded that all the tested exercises seemed to improve the patients with low back pain due to pregnancy.

Instead of prescribing bed rest or multiple drugs in patients with low back pain during pregnancy we recommend therapeutic exercises and ADL instructions that have been effective in this study.

\section{References}

1. Garhasbi A. Faghih Zadeh S The effect of exercise on the intensity of low back pain in pregnant women. Int J Gynaecol Obstet 2005 Mar, 88(3):271- 5.

2. Wu WH, Meijer OG, Uegaki K, Mens JM, Van Dieen JH, Wuisman Pl. et al. Pregnancy- related pelvic girdle pain. Terminology Clinica presentation \& Prevalence. Eur spine J 2004; 13: 575 - 89.

3. Fast A, Shapiro D, Ducommun EJ, Friedmann LW, Bouklas T, Floman Y. Low Back pain in pregnancy. Spine. $1987 ; 12$ (4): 368 - 371

4. Taslim M. U. Low Back Pain. An Overview. In Musculoskeletal Medicine. 2006; 301- 330.

5. Darryl B, Sneag, AB; John A. Bendo, MD. Pregnancyrelated Low Back Pain, ORTHOPEDICS 2007; 30:839.

6. Goran Berg et al, low back pain during pregnancy, Obstet \& Gynec Vol. 71, No. 1, January 1988. 